\title{
水平管粒体プラグ輸送における圧力損失予測式の導出* （粒子種類および管内径に対する高応用性）
}

\author{
河 府賢 治*1, 越 智 光 昭*1, 武 居昌 宏*1 \\ Derivation of Predicted Pressure Drop Equation \\ on Granular Particle Plug Transportation in Horizontal Pipe \\ (High Adaptability for Kinds of Particle and Pipe Diameter)
}

\author{
Kenji KOFU*2, Mitsuaki OCHI and Masahiro TAKEI \\ *2 Department of Mechanical Engineering, College of Science \& Technology, Nihon University, \\ 1-8-14 Kanda-Surugadai, Chiyoda-ku, Tokyo, 101-8308 Japan
}

\begin{abstract}
In a plug transportation that is one of gas-solid two-phase flow, the predicted equations on particle velocity within a plug and pressure drop in a horizontal pipe have been formulated. The agreement between values calculated by these equations and experiments that changed solid-air mass flow rate, pipe diameter, kinds of particle was obtained. The error between them is almost within $10 \%$. In order to confirm the validity of supposition to derive these equations, particle velocity distribution within a plug in the directions of flow and radius, and particle velocity transformation from a stationary bed to a plug have been analyzed by high speed camera and PIV. As a result, there is no particle velocity distribution in a plug, and particles are accelerated uniformly in extra part of a plug. Particles in a plug are fixed relative to each other and so they all move with the same velocity.
\end{abstract}

Key Words : Pressure Drop, Particle Velocity, Pipe Line, Gas-Solid Two-Phase Flow, PIV

\section{1. 緒言}

粉粒体輸送方式の一つである空気輸送は, ベルトコン ベア等の機械的輸送方式，あるいはコンテナなどの容 器を用いた輸送方式と比べ, 高速且つ衛生的に輸送 でき，人件費最小で稼動できるなど多くの長所を持つ. この空気輸送は低濃度高速輸送方式と高濃度低速輸送 方式の 2 つに大別できる. 最近では省エネルギー，管 路の摩耗や粒子の破損防止の観点から高濃度低速輸送 方式，通称プラグ輸送の採用が著しい．

このプラグ輸送ラインの設計において, 輸送コスト の低减化や輸送の確実性の観点から, 正確に所要動力 すなわち圧力損失を見積もる必要がある. そのため, これまで多くの研究者により研究され，プラグ輸送に

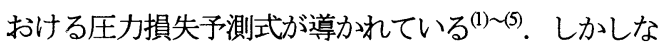
がら，これらの式は粒子輸送量や空気流量などの輸送 条件, 輸送粒子の種類, 輸送管内径などを変更した時 に計算値と実験值との誤差が大きくなるため，信頼性 の高い実用的な式とは言い難い，また，粒子形状によ り Ergun 式中の係数を変更する必要があるなどの問題

\footnotetext{
* 原稿受付 2007 年 3 月 8 日.

*1 正員, 日本大学理工学部(画101-8308 東京都千代田区神田 駿河台 1-8-14).

E-mail : kofu@mech.cst.nihon-u.ac.jp
}

もある (1) (3)．筆者らは静止粒子充填層内の圧力損失予 測式として，粒子形状および管内径を考慮した修正 Engun 式を提案した ${ }^{(の)}$.この式は, 実測值との誤差が $\pm 6 \%$ と精度が高く，さらに粒子種類，管内径および 空気速度に対する適用範囲も広い。しかしこの式をプ ラグ輸送に適用するためには，予備実験を行い，粒子 速度を測定する必要がある.

そこで本研究では，水平管プラグ輸送において，粒 子種類，管内径およひ輸送条件に対し応用性が高く, 予備実験が不要である実用的な圧力損失の予測式を導 出することを目的とする. さらに粒子の流動状態を測 定し, 予測式導出における仮定の妥当性の検証も行う.

\section{おもな記号}

$\begin{array}{lll}A & : \text { 管断面積 } & {\left[\mathrm{m}^{2}\right]} \\ D & : \text { 管内径 } & {[\mathrm{m}]} \\ d_{P} & : \text { 粒子径 } & {[\mathrm{m}]} \\ F & : \text { プラグ前後端応力 } & {[\mathrm{Pa}]} \\ g & : \text { 重力加速度 } & {\left[\mathrm{m} / \mathrm{s}^{2}\right]} \\ l_{e x} & : \text { 単一プラグ前後部長さ } & {[\mathrm{m}]} \\ l_{P} & : \text { 単一プラグ長さ } & {[\mathrm{m}]} \\ L_{P} & : \text { プラグ総長さ } & {[\mathrm{m}]}\end{array}$




$\begin{array}{lll}L_{T} & : \text { 輸送管長さ } & {[\mathrm{m}]} \\ M_{s} & : \text { 粒子質量流量 } & {[\mathrm{kg} / \mathrm{s}]} \\ P & : \text { 管内空気圧力 } & {[\mathrm{Pa}]} \\ \Delta P & : \text { 圧力損失 } & {[\mathrm{Pa}]} \\ U_{a} & : \text { 管内空気速度 } & {[\mathrm{m} / \mathrm{s}]} \\ U_{S P} & : \text { すべり速度 } & {[\mathrm{m} / \mathrm{s}]} \\ u_{s} & : \text { プラグ内粒子速度 } & {[\mathrm{m} / \mathrm{s}]} \\ W_{P} & : \text { プラグ速度 } & {[\mathrm{m} / \mathrm{s}]} \\ \varepsilon & : \text { 空䏚率 } & {[-]} \\ \mu_{w} & : \text { 摩擦係数 } & {[-]} \\ \rho_{a} & : \text { 空気密度 } & {\left[\mathrm{kg} / \mathrm{m}^{3}\right]} \\ \rho_{B} & : \text { かさ密度 } & {\left[\mathrm{kg} / \mathrm{m}^{3}\right]} \\ \rho_{S} & : \text { 粒子密度 } & {\left[\mathrm{kg} / \mathrm{m}^{3}\right]} \\ \sigma_{r} & : \text { 半径方向の粒子相互応力 } & {[\mathrm{Pa}]} \\ \sigma_{x} & : \text { 流れ方向の粒子相互応力 } & {[\mathrm{Pa}]} \\ \tau_{w} & : \text { 壁面摩擦応力 } & {[\mathrm{Pa}]} \\ \phi & : \text { 内部摩摖角 } & {[\mathrm{deg}]} \\ \phi_{s} & : \text { 粒子直線率 } & {[-]}\end{array}$

\section{2 予測式の導出}

図 1 に水平管における輸送安定状態のプラグを示す. 輸送安定状態のプラグ輸送では, プラグ前端において プラグ間の管底にある静止堆積層からプラグ内に粒子 を取り込み，プラグ後端において同量の粒子をプラグ 外一吐き出している ${ }^{(17)}$. 管断面全体を粒子が塞いで いる部分の長さをプラグ長さ $l_{P}$ とし, $l_{P}$ と静止堆積層と の間にある粒子層体積を管断面積 $A$ て除した長さを $l_{\mathrm{ex}}$ とする. $l_{P}$ 内の粒子は相互に固定された状態，つまり 一塊て輸送されるとし，プラグ内粒子速度 $u_{s}$ は主流お よび半径方向の位置に拘らず一定值と仮定する. さら に $l_{e x}$ 内の粒子は, 静止堆積層から $l_{P}$ までの間に等加速 されるとし, $l_{e x}$ 内の平均粒子速度を $0.5 u_{s}$ とする.

$l_{P}$ 内において, 長さ $d x$ の微小部分に作用する力の釣合 いを考える. $x$ だけの関数として全态力を仮定すると,

$$
\frac{d P}{d x}+\frac{d \sigma_{x}}{d x}+\frac{4 \tau_{w}}{D}=0
$$

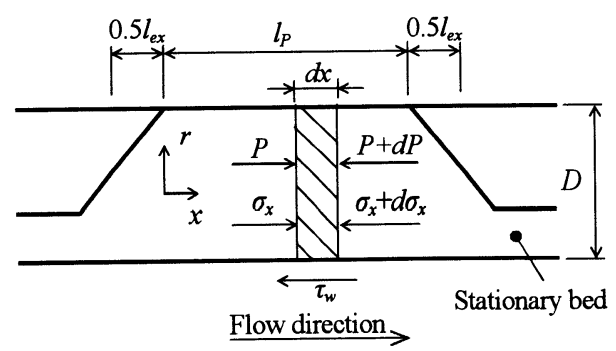

Fig.1 Pressure within a plug in horizontal pipe
となる. ここで $\sigma_{x}$ は流れ方向の粒子相互応力， $P$ は空 気圧力, $\tau_{w}$ (壁面摩擦応力, $D$ は管内径である. Konrad ${ }^{(1)}$ は半径方向の粒子相互応力 $\sigma_{r}$ に関し， $\sigma_{r}>\sigma_{x}$ となる受 動的崩壊において

$$
\begin{gathered}
\sigma_{r}=K_{W} \sigma_{x}+\left(K_{W}+1\right) c \cos \phi \cos \left(\omega+\phi_{w}\right) \\
K_{W}=\frac{1+\sin \phi \cos \left(\omega+\phi_{w}\right)}{1-\sin \phi \cos \left(\omega+\phi_{w}\right)} \\
\sin \omega=\frac{\sin \phi_{w}}{\sin \phi} \\
\tan \phi_{w}=\mu_{w}
\end{gathered}
$$

を導いた。 $\phi$ は内部摩擦角, $c$ は粒子同士粘着力である.

次に, プラグの重さによる管壁への応力 $P_{g}$ を考える. Konrad ${ }^{\left({ }^{()}\right)}$, Pan and Wypych ${ }^{(2)}$ および辻 ${ }^{(3)}$ らは静水圧理 論を適用し， $P_{g}$ を得ている. しかしここの場合粒子群 は固体であることから，著者らはプラグ重さを管壁表 面積で除した值を $P_{g}$ と考え

$$
P_{g}=\frac{\frac{1}{4} \rho_{B} \pi D^{2} g d x}{\pi D d x}=\frac{1}{4} \rho_{B} g D
$$

とする. プラグが岡体に近い状態で輸送される場合, 粒子は受動的崩壊に従う(1). そこで式(6)を式(2)にその まま加えることができるとすると

$$
\sigma_{r}=K_{W} \sigma_{x}+\left(K_{W}+1\right) c \cos \phi \cos \left(\omega+\phi_{w}\right)+\frac{1}{4} \rho_{B} g D
$$

となる. 輸送安定状態の場合, プラグ内の圧力損失を 一定として考えることができる. 故に式(1)(7)および

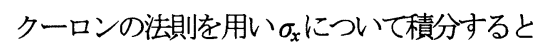

$$
\begin{aligned}
\sigma_{x}= & k \exp \left[-\frac{4 \mu_{w} K_{W}}{D} x\right]-\frac{\Delta P}{l_{P}} \frac{D}{4 \mu_{w} K_{W}} \\
& -\frac{\left(K_{W}+1\right) c \cos \phi \cos \left(\omega+\phi_{w}\right)}{K_{W}}-\frac{\rho_{B} g D}{4 K_{W}}-\frac{C_{w}}{\mu_{w} K_{W}}
\end{aligned}
$$

となる. $k$ は積分定数, $\Delta P$ はプラグ前後の圧力差, $\mu_{w}$ は摩擦係数， $C_{w}$ は管壁と粒子との粘着力である. Janssen の解析結果 ${ }^{(1)(8)}$ よりプラグ前後端 $\left(x=0, l_{P}\right)$ において $\sigma_{x}=F$ とする. 故に式(8)は

$$
\begin{array}{r}
\frac{\Delta P}{l_{P}}=\frac{4 \mu_{w} K_{W} F}{D}+\frac{4 \mu_{w}\left(K_{W}+1\right) c \cos \phi \cos \left(\phi_{w}+\omega\right)}{D} \\
+\rho_{B} g \mu_{w}+\frac{4 C_{w}}{D}
\end{array}
$$

となる.

次に，Fについて考える. $F$ に関しKonrad らは静止 堆積層と $l_{P}$ 内との運動量の差より得ている. ところが, 静止堆積層と $l_{P}$ との間に $l_{e x}$ があるため, Konrad らによ る $F$ は適用が難しいと言える. そこで著者らは $F を l_{P}$ と 


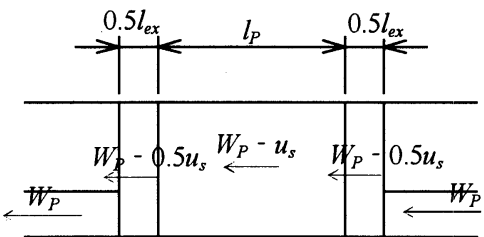

Fig.2 Particle velocity (Plug velocity axis)

$l_{e x}$ との境界における運動量の差より求める. 図 2 に示 すとおりプラグ速度 $W_{P}$ における座標系を考える. この 図より

$$
F=\frac{1}{2} \frac{G_{s}}{A} u_{s}
$$

となる.ここで $G_{s}$ は単位時間当たりにプラグ内に取り 込まれ吐き出される粒子の質量である. プラグ前後端 において粒子の吸い込みと吐き出しがあるため， $u_{s}$ と $W_{P}$ とは異なる. 図 2 から $G_{s}$ は

$$
G_{s}=A \rho_{B}\left(W_{p}-u_{s}\right)
$$

と表せる. Brooke Benjamin ${ }^{(9)}$ の気液二相流理論を $W_{P}$ と $u_{s}$ との関係に適用すると

$$
W_{p}=u_{s}+0.542 \sqrt{g D}
$$

と表わせる. 式(10)〜(12)より

$$
F=0.271 \rho_{B} u_{S} \sqrt{g D}
$$

となる. 非粘着性粒子を考え

$$
C_{w}=c=0
$$

とすると，式(13)および(14)より式(9)は

$$
\frac{\Delta P}{l_{P}}=\mu_{w} \rho_{B} g+1.084 \mu_{w} K_{W} \rho_{B} u_{s} \sqrt{\frac{g}{D}}
$$

となる.

また，このプラグ内の圧力損失に関して Ergun 式(10)が 知られている. しかし，この Ergun 式による圧力損失 は $D$ および粒子形状により誤差が生じることが知られ ている ${ }^{(11)(12)}$ ．そのため著者らは，Dおよび粒子形状を 考慮した修正Ergun 式

$$
\begin{aligned}
\frac{\Delta P}{l_{P}}=150\left(1+\frac{2 d_{P}\left(1-0.645 \phi_{s}\right)}{3 D(1-\varepsilon)}\right)^{2} \frac{\eta(1-\varepsilon)^{2}}{\left.\varepsilon^{3}\left(1-0.645 \phi_{s}\right) d_{P}\right\}^{2}} U_{S P} \\
+1.75 \frac{\rho_{a}(1-\varepsilon)}{\varepsilon^{3}\left(1-0.645 \phi_{s}\right) d_{P}} U_{S P}{ }^{2}
\end{aligned}
$$

を提案 ${ }^{(6)}$ した. $\eta$ は空気粘度, $d_{P}$ は粒子径, $\rho_{a}$ は空気 密度, $\varepsilon$ は空隙率 $\left(=1-\rho_{B} / \rho_{S}\right), U_{S P}$ はすべり速度, $\phi_{s}$ は粒子直線率である。 $\phi_{s}$ は，図 3 に示寸通り粒子 2 次元投影画像における周長 $l_{s}$ と直線部の長さ $l_{i}$ との比

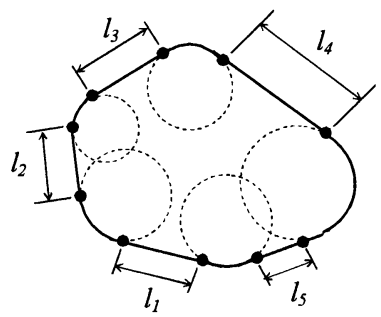

Fig.3 Ratio of straight length

である. 直線部の数を $N_{s}$ とすると, 式(17)として与えら れる.

$$
\phi_{s}=\sum_{i=1}^{N_{s}} l_{i} / l_{s}
$$

偣は，0から 1 の実数で与えられ，球形粒子は 0 , 立 方体粒子は 1 となる.ここで $U_{\mathrm{Sp}}$ は空気速度 $U_{a}$ を用い，

$$
U_{S P}=U_{a}-u_{s}
$$

とすると, 式(15)(16)および(18)から

$$
\begin{aligned}
u_{s}{ }^{2}-\left(\frac{a}{b \rho_{a}}+2 U_{a}+\right. & \left.\frac{1.084 \mu_{w} K_{W} \rho_{B}}{b \rho_{a}} \sqrt{\frac{g}{D}}\right) u_{s} \\
& +\frac{a U_{a}}{b \rho_{a}}+U_{a}{ }^{2}-\frac{\rho_{B} g \mu_{w}}{b \rho_{a}}=0
\end{aligned}
$$

が導ける. ここで

$$
\begin{gathered}
a=150\left(1+\frac{2 d_{P}\left(1-0.645 \phi_{s}\right)}{3 D(1-\varepsilon)}\right)^{2} \frac{\eta(1-\varepsilon)^{2}}{\varepsilon^{3}\left\{\left(1-0.645 \phi_{s}\right) d_{P}\right\}^{2}} \\
b=1.75 \frac{(1-\varepsilon)}{\varepsilon^{3}\left(1-0.645 \phi_{s}\right) d_{P}}
\end{gathered}
$$

である. 式(19)より $u_{s}$ に関して $2 つ の$ 解が得られるが, 大きい方の值は負のすべり速度を与えるため, 小さい 方の值を用いる. 故に

$u_{s}=\frac{1}{2}\left(\frac{a}{b \rho_{a}}+2 U_{a}+\frac{1.084 \mu_{w} K_{W} \rho_{B}}{b \rho_{a}} \sqrt{\frac{g}{D}}\right)$

$-\frac{1}{2} \sqrt{\left(\frac{a}{b \rho_{a}}+2 U_{a}+\frac{1.084 \mu_{w} K_{W} \rho_{B}}{b \rho_{a}} \sqrt{\frac{g}{D}}\right)^{2}-4 \times\left(\frac{a U_{a}}{b \rho_{a}}+U_{a}^{2}-\frac{\rho_{B} g \mu_{w}}{b \rho_{a}}\right)}$

となる.

プラグ輸送では，粒子の塊であるプラグ部だけでな く空気の塊であるスラグ部もあるため, この部分も含 めた圧力損失の式一拡張を行う必要がある. 管内に存 在する総プラグ長さ $L_{P}$ と管長 $L_{T}$ との関係について近似 的に

$$
L_{P}=\frac{M_{s} L_{T}}{A \rho_{B} u_{s}}
$$

が導ける. 空気スラグ部の圧力損失は，プラグ部に比 べ非常に小さいため，この部分の圧力損失を無視する. 式(15)の $l_{P}$ を $L_{P}$ に置き換え，式(23)を代入すると 


$$
\frac{\Delta P}{L_{T}}=\frac{M_{s}}{A \rho_{B} u_{s}}\left[\rho_{B} g \mu_{w}+1.084 \mu_{w} K_{W} \rho_{B} u_{s} \sqrt{\frac{g}{D}}\right]
$$

となる. この式より，水平管における圧力損失を求め ることができる.

\section{3. 実験装置および方法}

図 4 に本研究に用いた実験装置を示す。輸送管は $D=25.6,38.0$ および $50.0 \mathrm{~mm}$ の 3 種類である. またライ ン全長は約 $13 \mathrm{~m}$ であり，全て透明なアクリル管である. 空気源にエアーコンプレッサを，その圧縮空気を溜め るためにエアーチャンバを使用し，その圧縮空気を減 圧するためにエアーチャンバの後に減圧弁を取り付け た. その後方に, 空気流量 $Q_{a}$ 測定のために, フロー メータを設置し, 粒子輸送量 $M_{s}$ 測定のために, ブロー タンクにロードセルを取り付けた. また図 4 に示すと おり，輸送管 2 ケ所に圧力センサを設置し，圧力を測 定した. プラグ輸送安定時において $0.05 \mathrm{sec}$ 毎 $30 \mathrm{sec}$ 連続 測定したときの平均值を管内圧力 $P$ とした. 減圧弁と 粒子供給弁で安定状態となる輸送条件を設定し, 実験 を行った. 輸送条件は, $U_{a}=1.1 \sim 5.0 \mathrm{~m} / \mathrm{s}$, 固気質量流 量比 $m_{T}=21 \sim 105$ である.

また圧力損失予測式で仮定されているプラグ間にあ る堆積層から $l_{P}$ 内一取り込まれるまでの粒子速度の変 化，およびプラグ内の主流および半径方向位置による 粒子速度分布を調べるため, 高速度カメラ（フォトロン 製, FASTCAM-APX RS 250K）と PIV を用いた. 高速 度カメラによる撮影は, $1024 \times 1024$ pixels, 2000fps に て行った. PIV の検查領域は $45 \times 45$ pixel とし，相関係 数は 0.7 とし解析を行った. 解像度は, 1 画素 $0.056 \mathrm{~mm}$ である．なおプラグ内の粒子は，撮影画像より回転が 無いため, 回転による PIV の結果への影響は無いと言 える. さらに PIV による粒子速度の值の妥当性を確認 するため，および $u_{s}$ に関する実験值を測定するため, 30fps のデジタルビデオカメラ（ソニー製，DCR-VX2000） を用いた. ビデオカメラによる $u_{s}$ 測定のため, 一部の 粒子を着色した. 図 5 に示寸通り，着色された粒子を 見つけ，そこから幾つかフレームを進め，その移動距 離とフレーム数から $u_{s}$ を求めた. 高速度カメラおよび デジタルビデオカメラを図 4 の破線部に設置した. ビ デオカメラによる測定は全条件, 高速度カメラおよび PIV による測定は，代表として $D=38$ および $50 \mathrm{~mm}$ にお けるポリエチレンペレット, $D=38 \mathrm{~mm}$ におけるプラス チックペレットにて行った.

実験に用いた粒子は, 菜種, ポリスチロールペレット, ポリエチレンペレット，ニポロンハードおよびプラス チックペレットであり，物性值を表1に示寸.

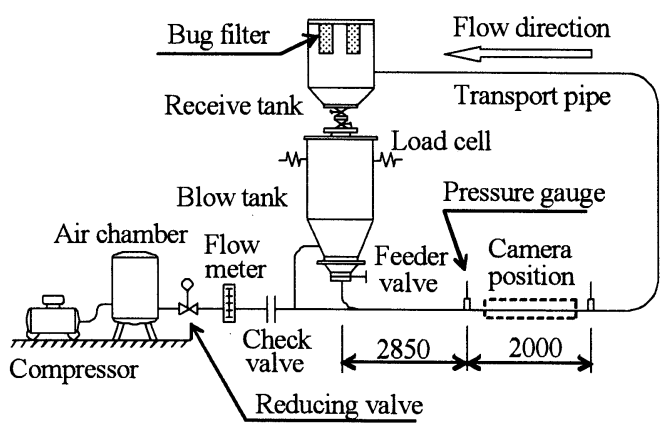

Fig.4 Experimental apparatus

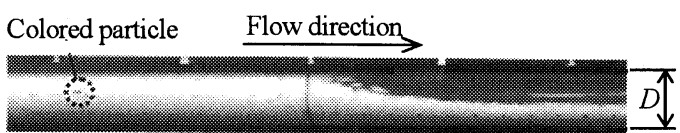

(a) Standard

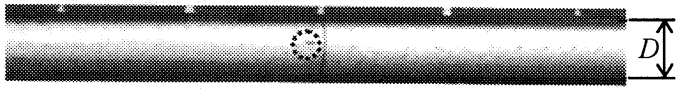

(b) After some frames

Fig.5 Measurement of particle velocity by digital video

Table1 Particle properties

\begin{tabular}{cccccc}
\hline Solids & Rapseed & $\begin{array}{c}\text { Polystyrol } \\
\text { pellet }\end{array}$ & $\begin{array}{c}\text { Polyethy } \\
\text {-lene pellet }\end{array}$ & $\begin{array}{c}\text { Nipolon } \\
\text { hard }\end{array}$ & $\begin{array}{c}\text { Plastic } \\
\text { pellet }\end{array}$ \\
\hline $\begin{array}{c}\text { Mean particle } \\
\text { diameter } \\
d_{P}(\mathrm{~mm})\end{array}$ & 1.98 & 2.80 & 3.27 & 3.54 & 6.00 \\
\hline $\begin{array}{c}\text { Straight } \\
\text { length ratio } \\
\phi_{s}\end{array}$ & 0.020 & 0.369 & 0.184 & 0.132 & 0.000 \\
\hline $\begin{array}{c}\text { Voidage } \\
\varepsilon\end{array}$ & 0.420 & 0.383 & 0.378 & 0.416 & 0.461 \\
\hline $\begin{array}{c}\text { Bulk density } \\
\rho_{B}\left(\mathrm{~kg} / \mathrm{m}^{3}\right)\end{array}$ & 435 & 678 & 591 & 531 & 572 \\
\hline $\begin{array}{c}\text { Particle density } \\
\rho_{S}\left(\mathrm{~kg} / \mathrm{m}^{3}\right)\end{array}$ & 1050 & 1100 & 950 & 910 & 1061 \\
\hline $\begin{array}{c}\text { Angle of } \\
\text { internal friction } \\
\phi(\text { deg })\end{array}$ & 25.3 & 35.4 & 27.0 & 30.7 & 30.0 \\
\hline $\begin{array}{c}\text { Coefficient of } \\
\text { friction } \\
\mu_{w}^{*}\end{array}$ & 0.365 & 0.439 & 0.360 & 0.288 & 0.250 \\
\hline Shape & Sphere & Column & Disk & Oval & Sphere \\
\hline
\end{tabular}

* Against polyacrylic plate

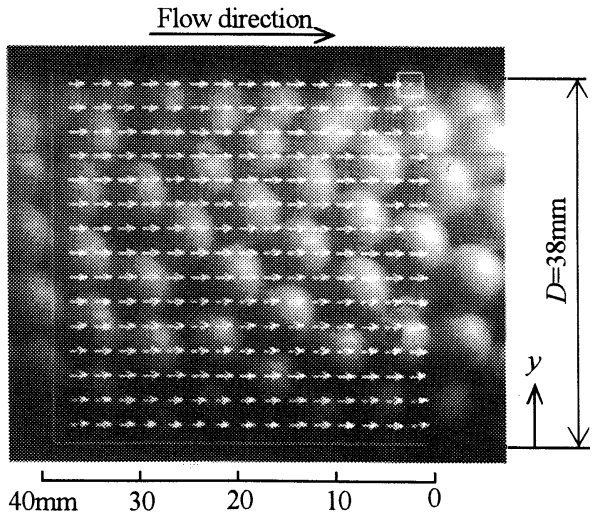

Fig.6 Velocity vector in a plug (Plastic pellet, $m_{T}=62.8$ ) 


\section{4. 実験結果}

PIV によるプラグ内粒子の速度ベクトルの一例（プ ラスチックペレット, $\left.m_{T}=62.8\right)$ を図 6 に示す. ベクト ルは 50 フレーム間の平均值とする. 図 6 よりベクトル は全て主流方向のみ向いており, 主流と直角となる $y$ 方向に粒子が動かないことがわかる。

また，この PIV による $u_{s}$ の妥当性について調べる. 主流方向の $u_{s}$ に関し横軸にビデオカメラによる值, 縦 軸に高速度カメラと PIVによる值をとり, 図 7 に示寸。 ビデオカメラによる $u_{s}$ は, $l_{P}$ 内においてランダムに測 定された 100 粒の粒子の平均值とした. PIVによる $u_{s}$ は $D \times D$ の範用内における 50 フレーム間およびプラグ 3 個の平均値とした. 図 7 から, ビデオカメラによる測 定值と PIV による值とが近い值となることが分かる. この結果および解析において誤べクトルがほとんど見 られなかったことから，PIV による値は妥当であると 言える.

さらに，主流および $y$ 方向位置に対する粒子速度分 布を調べるため, 横軸に PIVによる粒子速度, 綐䡛に 管底加らの距離 $y$ と $D$ との比 $y / D$ をとり, 図 8 に示す. 図 8 から $y D$ に拘らず，ほぼ一定の速度を示している ことがわかる. PIV による測定值は，管壁面における

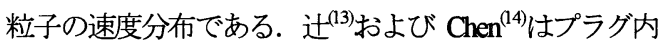
の粒子速度は $y$ 方向位置, あるいは管断面位置により 分布があると考えている. しかし本実験において, $l_{P}$ 内の壁面部の粒子が回転していないこと，および田中(15) らのシミュレーションによる研究結果において, 壁面 付近と管中心付近の速度がほぼ等しいことから， $l_{P}$ 内 の粒子は管断面位置に拘らず等速で動くと考えても良 いと言える.

また, プラグ間の静止堆積層から $l_{P}$ 内に取り込まれ るまでの主流方向の粒子速度変化を調べる. 主流方向 位置が同じであり，y 方向位置が異なる各検査領域を とり, 各検査領域における主流方向粒子速度の時系列 変化を PIV より得る. この領域における粒子速度平均 値の時系列変化の一例 (ポリエチレンペレット, $D=50 \mathrm{~mm}$, $\left.m_{T}=40.2\right)$ を図 9 に示寸．なお，管内を浮遊する粒子速 度を除くため，撮影画像を観察しながら，管壁まで粒 子が満たされている検查領域の速度の平均值を粒子速 度とした. 図 9 より, プラグ内の粒子は流れ方向の位 置に拘らず一定の速度で動くことがわかる. この結果 および図 6 と図 8 における結果から, プラグ内の粒子 は主流および半径方向位置に関係なく一定の速度で動 く,つまりプラグ内の粒子は相互に固定され，一塊で 輸送されていると言える. また図9から，プラグ間の管

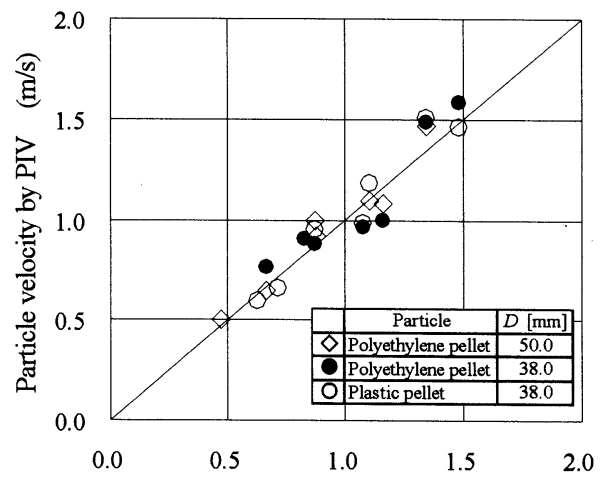

Particle velocity by digital video camera $(\mathrm{m} / \mathrm{s})$

Fig.7 Confirmation on validity of analysis by PIV

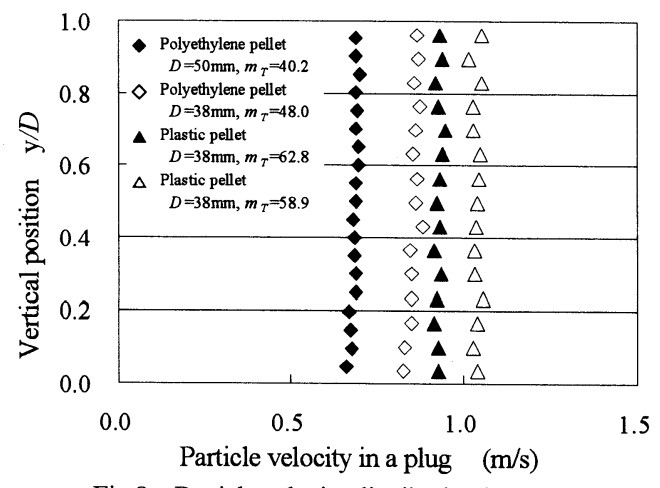

Fig.8 Particle velocity distribution in a plug

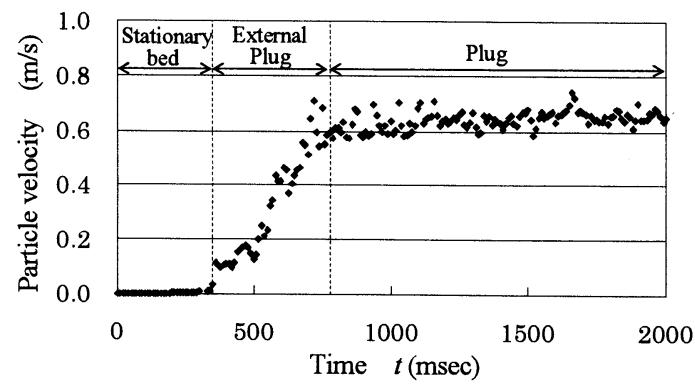

Fig.9 Particle velocity at each position

(Polyethylene pellet, $D=50 \mathrm{~mm}, m_{T}=40.2$ )

底部に静止状態で堆積している粒子が $l_{e x}$ 内て等加速され ていることがわかる. 故に $l_{e x}$ における粒子速度を $0.5 u_{s}$ として考えることができると言える.

\section{5. 圧力損失予測式の検討}

修正 Ergun 式を導入したプラグ内粒子速度式(22), および圧力損失予測式(24)の実用性に関し，著者らを 含めた国内外の研究者 (Konrad ${ }^{(1)}$, Pan and Wypych ${ }^{(2)}$, 辻 ${ }^{(3)}, \mathrm{Mi}$ and $\mathrm{Wypych}^{(4)}$ おび $\mathrm{Aziz}^{(5)}$ の式について検討 を行う。 

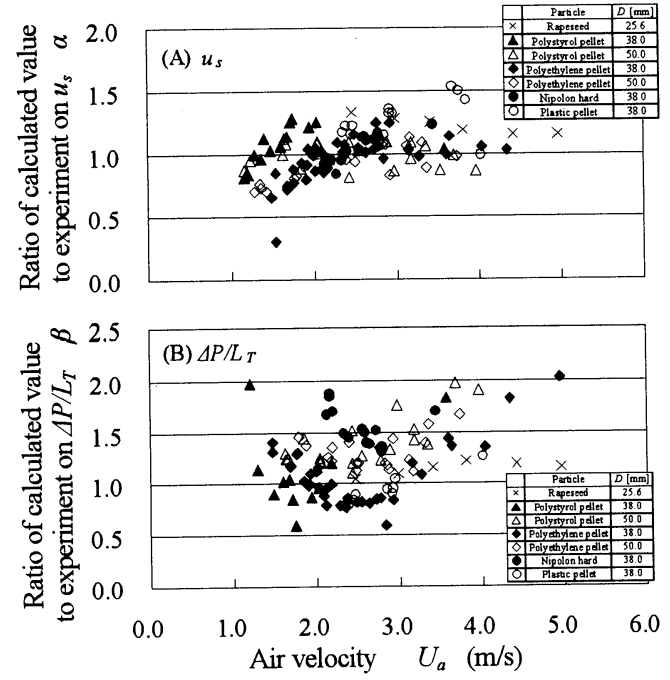

Fig.10 Comparison of experiment with calculation (Konrad)
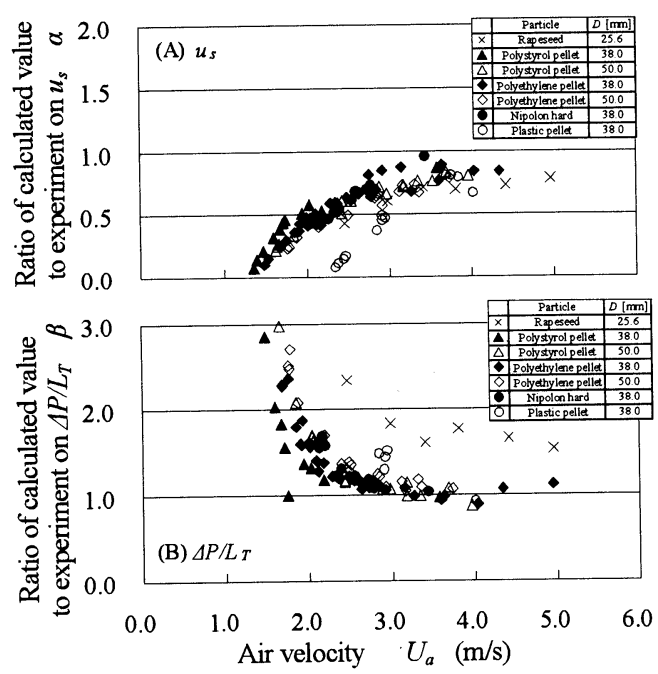

Fig. 11 Comparison of experiment with calculation (Pan and Wypych)

各研究者ごとに，横軸に $U_{a}$ をとり，綐軸に $u_{s}$.または $\Delta P / L_{T}$ に関する計算值と実験值との比をとり, 図 10〜15 に示す．計算值と実験值との比において $u_{s}$ に関する比 を $\alpha, \Delta P L_{T}$ に関する比を $\beta$ とする. $u_{s}$ はより多くのプ ラグの平均をとるため，および PIV を用いた図 8 およ び 9 から $l_{P}$ 内位置により $u_{s}$ は変わらないと言えるため, ビデオカメラによる值を用いた. $\Delta P / L_{T}$ の計算で必要 となる粒子速度は，各研究者の式により計算される值 を用いた. 但し，Aziz は速度に関する式を示していな いため, Aziz の $u_{s}$ に関する計算値と実験值との比較は 行わず, $\Delta P L_{T}$ の計算で必要となる粒子速度は実験值を用 いた. またPan and Wypych，およびMi and Wypych は，
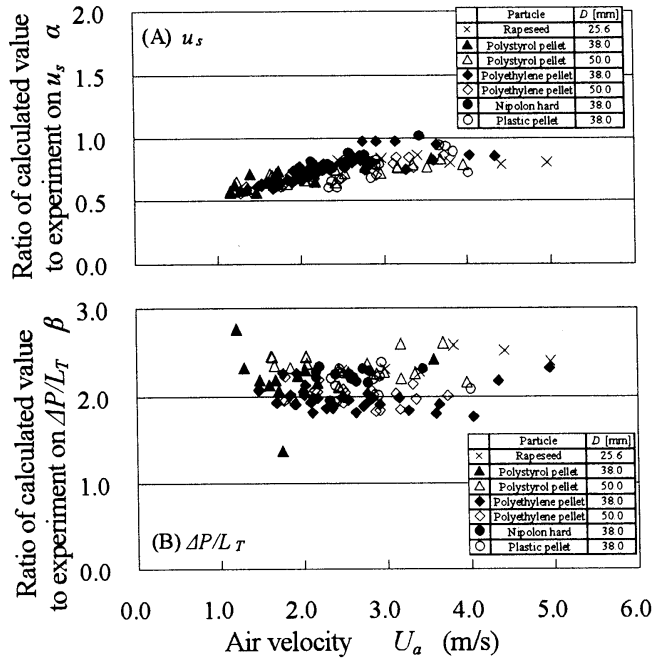

Fig. 12 Comparison of experiment with calculation (Tsuji)
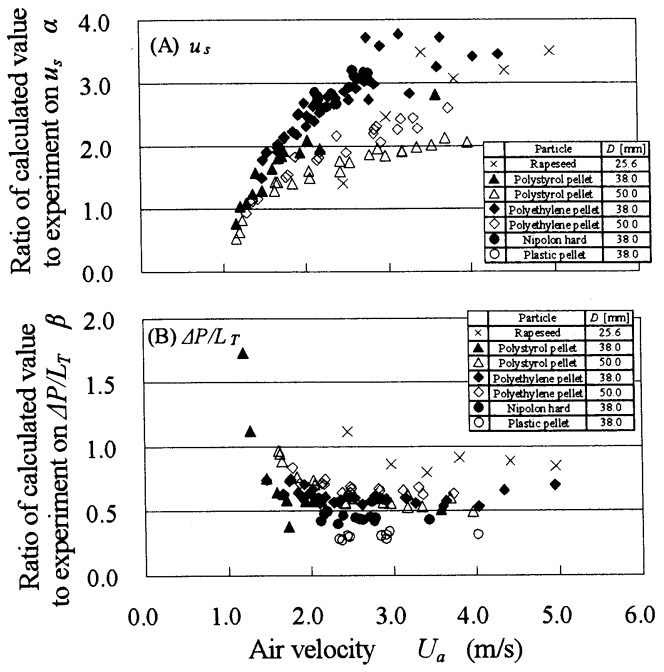

Fig. 13 Comparison experiment with calculation (Mi and Wypych)

$u_{s}$ ではなく $W_{P}$ の式を導いているため, 式(12)を用いて $u_{s}$ を求め, 実験值との比較を行った. なお計算に必要 な $\rho_{a}$ は，管内圧より得られる実験值を用いた。

Konrad, Pan and Wypych，辻，Mi and Wypych および Aziz らの式は, 粒子の重さについて静水圧理論を適用 している点，および $F$ を求めるとき Aziz は $U_{a}$ と $W_{P}$ と の差, その他の研究者は, 静止堆積層と $l_{P}$ 内との粒子 速度差を用いている点が著者らの式と異なる，また Konrad は $U_{\text {SP }}$ 空塔粒子速度を導入している点, Pan and Wypych および Mi and Wypych はプラグを主動的崩壊 として考えている点, Pan and Wypych は $U_{\mathrm{SP}}$ を $U_{a}$ と $W_{P}$ との差と考えている点が著者らの式と異なる. 
図 10(A)より Konrad の式による 分布しており，誤差が大きいことがわかる.これは実在 しない空塔粒子速度を $U_{S P}$ 一適用したため，誤差が生じ たと考えられる. また図 10(B)から， $U_{a}=2.0 \sim 3.0 \mathrm{~m} / \mathrm{s}$ に おいて, $D=38 \mathrm{~mm}$ におけるポリエチレンペレット，プ ラスチックペレットおよび菜種の場合， $\beta$ は 1.0 に近 く計算値と実験值に合致性が見られるが，他の粒子お よび他の条件では全く合致性が見られないことがわか る. さらに $\beta$ が 1.0 より大きいことがわかる.この結 果から Konrad の式による圧力損失は，実際の值より大 きく見積もっている，特定の粒子および輸送条件しか 適用できないと言える.

図 11(A)(B)より Pan and Wypych の式は，菜種を除き $U_{a}>3.0 \mathrm{~m} / \mathrm{s}$ において $\alpha, \beta$ とも 1.0 に近く, $u_{s}, \Delta P / L_{T}$ とも 良い合致性を示している. しかし $U_{a}<3.0 \mathrm{~m} / \mathrm{s}$ では $\alpha, \beta$ とも 1.0 と隔たりが生じ，誤差が大きくなることがわ

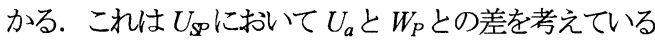
ためと言える. $U_{a}$ が大きくなると $u_{s}$ が大きくなり $W_{P}$ も 大きくなる. このとき, 式(12)中の $0.542 \sqrt{g D}$ の影響が 小さくなる. ところが $U_{a}$ が小さい場合, $0.542 \sqrt{g D}$ の影 響が大きくなり，誤差が生じたと考えられる. 故に $U_{S P}$ は $U_{a}$ と $W_{P}$ との差では考え難いと言える.

図 12(A)(B)より辻の式は，実験值と比べ $\alpha$ が 1.0 よ り小さく, $\beta$ が 2.0 前後と大きくなっている. これは, 静水圧理論を適用した重力による圧力損失一の影響, およひ静止層と $l_{P}$ との速度差で考えた $F$ による圧力損 失を実際の值より大きく見積もっているためと考えら れる.

図 13(A)(B)より Mi and Wypych らの式による $\alpha$ およ び $\beta$ は，全く実験值と同様の傾向を示していない，Mi and Wypych は $u_{s}$ に関し，特定の条件における実験值か ら $U_{a}$ との関係式を導いており，応用性に欠けるため誤 差が生じたと考えられる.

図 14(B)より Aziz の式による $\beta$ に関し，計算值と実験 值とに全く合致性が見られないことがわかる. この結果 より，粒子流動による圧力損失は， $U_{a}$ と $W_{P}$ との差で考 え難いと言える.

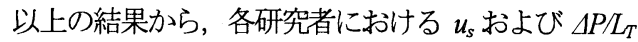
に関する計算值と実験值とに誤差が生じることがわか る. ところが図 15(A)(B)に示寸著者らの式による $\alpha$ お よび $\beta$ は，粒子種類，管内径，空気速度などの輸送条 件に拘らず，ほぼ 1.10 から 0.90 の範囲内に収まること がわかる．故に著者らの $u_{s}$ の式および $\Delta P / L_{T}$ の予測式 は，実験值と $\pm 10 \%$ の誤差範囲内に収まる適用範用の 広い式であると言える。これは本研究における $U_{S P}$ の 取り方, 重力による圧力損失一の影響, および $F$ の決定

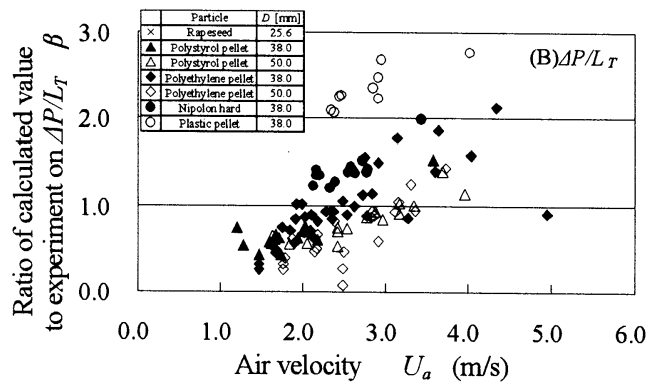

Fig. 14 Comparison experiment with calculation (Aziz)

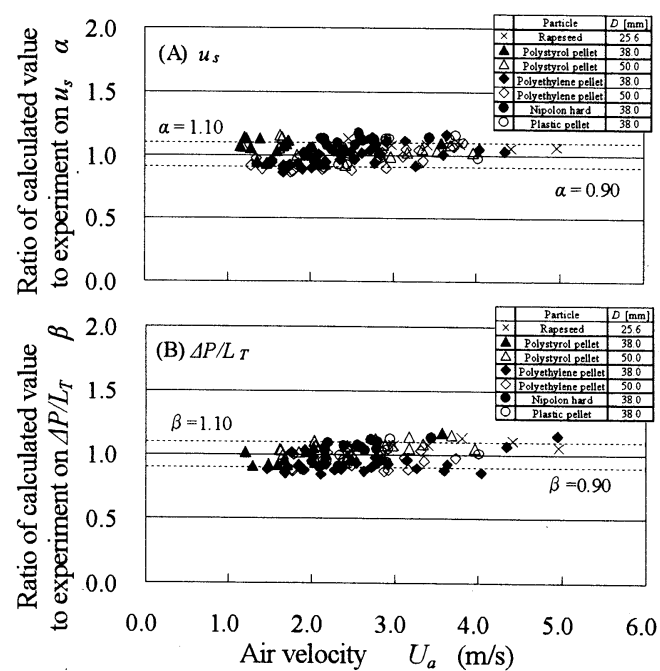

Fig. 15 Comparison of experiment with calculation (This study)

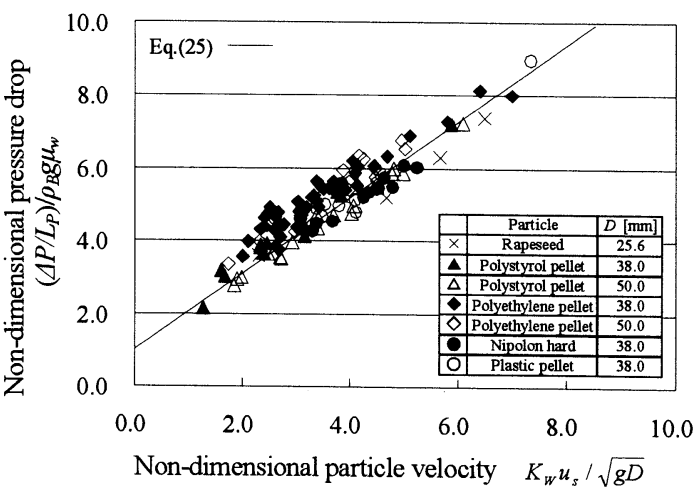

Fig.16 Pressure drop versus particle velocity

方法が適切であったためと考えられる。

さらに，式(24)による重力および粒子流動それぞれ に起因する圧力損失見積りの妥当性についても調べる. 横軸に無次元粒子速度 $K_{w} u_{s} / \sqrt{g D}$, 縦軸に無次元プラ グ内圧力損失 $\left(A P / L_{P}\right) / \rho_{B} g \mu_{w}$ をとり図 16 に示寸. 図中 のプロット点は，測定された $\triangle P$ を式(23)から計算され る $L_{P}$ および $\rho_{B} g \mu_{w}$ で除した值である. なお式(23)の $u_{s}$ 
には，実験值を用いた．また図中の実線は，式(24)を (23)および $\rho_{B} g \mu_{w}$ て除すことで得られる次の式(25)

$$
\frac{\Delta P}{L_{P}} \cdot \frac{1}{\rho_{B} g \mu_{w}}=1+1.084 \frac{K_{W} u_{s}}{\sqrt{g D}}
$$

により計算で求められる予測線である.ここに，式(25) の右辺第一項は粒子の重力による圧力損失を表し，右 辺第二項はプラグ前後の粒子吸込みと吐出しを伴う粒 子流動による圧力損失を表している. 図 16 において, 予測線の $y$ 切片が重力による圧力損失, その傾きが $u_{s}$ の増加に対する粒子流動による圧力損失の増加率を表 している. この図 16 より, 式(25)と実験值とが全ての 粒子種類，管内径およひ輸送条件において，ほぼ一致 していることがわかる. この結果，著者らの圧力損失 予測式(24)は, 重力による影響および粒子流動による 影響とも適切に見積もっており，応用性が高く，精度 が高い式であると言える.

\section{6. 結}

本報では, 水平管内における粒体プラグ輸送に関し， プラグ内粒子の流動状態と輸送特性について分析した. 実験に用いた粒子は, 菜種, ポリスチロールペレット， ポリエチレンペレット, ニポロンハードおよびプラス チックペレットである. 管内径は 25.6, 38.0, 50.0mm, 管長（輸送距離）は約 $13 \mathrm{~m}$ でアクリル透明管である. また輸送条件は空気速度が $1.1 \sim 5.0 \mathrm{~m} / \mathrm{s}$, 固気質量流 量比は 21〜105 である. その結果, 以下の結論を得た.

(1) 高速度カメラおよびPIVによる測定の結果, 壁面 付近におけるプラグ内の粒子速度は，位置に拘ら ず一定值となる.この結果および田中らの研究結 果から，プラグ内の粒子は粒子相互で固定された 状態で輸送されていると言える.

(2) 高速度カメラおよびPIVによる測定の結果，プラ グ内に取り込まれる粒子は，静止充填層から等加 速されプラグ内に取り込まれる. しかしプラグ内 に取り込まれるとほぼ等速で粒子は動く.

(3) 本研究において, 修正 Ergun 式を導入したプラグ内 粒子速度式(22), および圧力損失予測式(24)を導出し た. これらの式による予測值と実験值との誤差は, プラグ内粒子速度および圧力損失ともほぼ $\pm 10 \%$ の誤差範囲内に収まる. さらに, 重力および粒子流 動に起因する各圧力損失に関し，式(24)による見積 りは，適切であると言える.

\section{文献}

(1) Konrad, K., Prediction of the pressure drop for horizontal dense phase pneumatic conveying of particles, Proceedings of 5 th conference BHRA Fluid engineering, Paper E1 (1986), pp.225-244

(2) R.Pan, P.W.Wypych, Pressure drop and slug velocity in low-velocity pneumatic conveying of bulk solids, Powder Technology, Vol.94 (1997), pp. 123-132

(3) Tsuji,Y., Pneumatic transportation basic in Japanese, Yokendo (1984), pp.114-136

(4) B.Mi, P.W.Wypych, Pressure drop prediction in low-velocity pneumatic conveying, Powder Technology, Vol. 81 (1994), pp.125-137

(5) A.B.Aziz and G.E.Klinzing, Dense phase plug flow transfer -The 1-inch horizontal flow-, Powder Technology, Vol. 62 (1990), pp.41-49

(6) Kofu, K., Ochi, M., Takei, M., Proposal of Ergun' s Equation Modified with Ratio of Straight Length to Particle Perimeter and Pipe Wall Effect, Journal of the Society of Powder Technology, Japan, Vol.44,No.4(2007), pp.259-266

(7) Artur J. Jaworski, Tomasz Dyakowski, Investigations of flow instabilities within the dense pneumatic conveying system, Powder Technology, Vol.125,(2002), pp.279-291

(8) Janssen, H.A., Versuche uber Getreidedruck in Silozellen, Z.ver.deut.Ing.,39, 1045(1895. In German)

(9) Brooke Benjamin,T., Gravity currents and related phenomena,The Journal of Fluid Mechanics, Vol.31,Part2,section3(1968), pp.209-248

(10) Ergun, S., Fluid flow through packed columns, Chemical Engineering Progress, Vol.48, No.2 (1952), pp.89-94

(11) D.Nemec and J.Levec, Flow through packed reactors, Chemical Engineering Science, Vol.60, (2005), pp.6947-6957

(12) R. Yamazaki, Kozeny-Carman's Equation, Journal of the Society of Powder Technology, Japan, Vol.11,No.71(1974), pp.428-43 (in Japanese)

(13) Tsuji, Y., Morikawa, Y., Plug flow of coarse particles in a horizontal pipe, Journal of Fluids Engineering Transactions of the ASME, Vol.104 (1982), pp.198-206

(14) Dongming Chen, James F.Klausner, Renwei Mei, A fluid mechanics approach to describing the behavior of pneumatically conveyed powder plugs, Powder Technology, Vol.124(2002), pp.127-137

(15) Tanaka, T., Ishida, T., Tsuji, Y., Direct numerical simulation of granular plug flow in a horizontal pipe (the case of cohesionless particles), Transactions of the Japan Society of Mechanical Engineers, Series B, Vol.57, No.534(1991), pp.456-463 